\section{Endoscopic treatment using a knife to correct complete anastomotic obstruction following rectal cancer surgery}

Anastomotic stenosis is a well-recognized and troublesome complication following colorectal surgery. Conventionally, cases of complete obstruction have been treated conservatively with a permanent stoma, or have been managed by reoperation with its accompanying risks of morbidity [1-4]. We report successful endoscopic treatment using a knife in a patient with complete anastomotic obstruction following rectal surgery.

A 77-year-old woman underwent laparoscopic surgery for rectal cancer, with a low anterior resection, colorectal anastomosis, and a diverting loop ileostomy to protect the anastomosis. Four months after the operation, digital rectal examination revealed anastomotic obstruction. Colonoscopy showed complete closure of the anastomotic site at $6 \mathrm{~cm}$ from the anal verge ( Fig. 1). We attempted endoscopic management of the obstructed anastomotic site while preparing for surgery should it become necessary ( Video 1 ).

First, a small incision was carefully made to create a hole at the center of the obstructed anastomosis, using the DualKnife (KD-650L; Olympus, Tokyo, Japan) in the Endocut-Q mode with effect 2 (VIO 300D; Erbe Elektromedizin GmbH, Tübingen, Germany) ( Fig.2). An insulation-tipped knife (ITknife2, KD-611L; Olympus) was then used to enlarge the hole. Following this, an ultrathin endoscope with a $5.0 \mathrm{~mm}$ diameter (GIF-XP260; Olympus) was inserted through the created hole to confirm continuity with the proximal colon. Further circumferential excision with the ITknife 2 proceeded along the inner border of the surgical staples ( Fig.3).

\section{Video 1}

Endoscopic treatment using the DualKnife and ITknife2 (Olympus, Tokyo, Japan) for anastomotic site obstruction following rectal cancer surgery.
At the end of the procedure, the colonoscope was able to pass freely through the widened hole ( $\bullet$ Fig.4). There were no complications, such as bleeding or perforation, either during or after the procedure. The ileostomy was closed 2 months later, and there was no disturbance in the patient's stool passage. We were not able to achieve a "dual approach" using colonoscopy, reaching the anastomosis site through the ileostomy, because the bowel was too long. Although fluoroscopy can be helpful for establishing continuity with the proximal colon, direct observation using an ultrathin endoscope through a small opening might be another feasible method. We suggest that an endoscopic approach using a knife could be considered for the management of anastomotic obstruction following surgery.

\section{Endoscopy_UCTN_Code_TTT_1AT_2AZ}

\section{Competing interests: None}

\section{Soon Man Yoon ${ }^{1}$, Taek-Gu Lee ${ }^{2}$, Joung Ho Han', Hee Bok Chae', Seon Mee Park ${ }^{1}$, Sei Jin Youn ${ }^{1}$, Sang-Jeon Lee ${ }^{2}$}

${ }^{1}$ Department of Internal Medicine, Chungbuk National University Hospital, Chungbuk National University College of Medicine, Cheongju, Korea

2 Department of Surgery, Chungbuk National University Hospital, Chungbuk National University College of Medicine, Cheongju, Korea

\section{References}

1 Luchtefeld MA, Milsom JW, Senagore A et al. Colorectal anastomotic stenosis. Results of a survey of the ASCRS membership. Dis Colon Rectum 1989; 32: 733-736

2 Schlegel RD, Dehni N, Parc $R$ et al. Results of reoperations in colorectal anastomotic strictures. Dis Colon Rectum 2001; 44: $1464-$ 1468

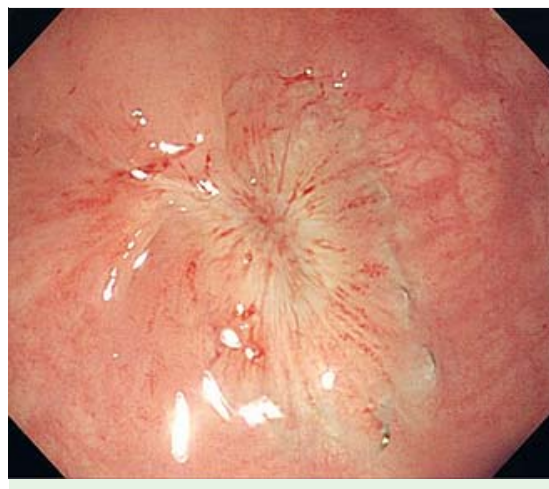

Fig. 1 Complete obstruction of the anastomotic site after primary resection of rectal cancer. Surgical staples were observed around the circumference of the obstructed anastomotic site.

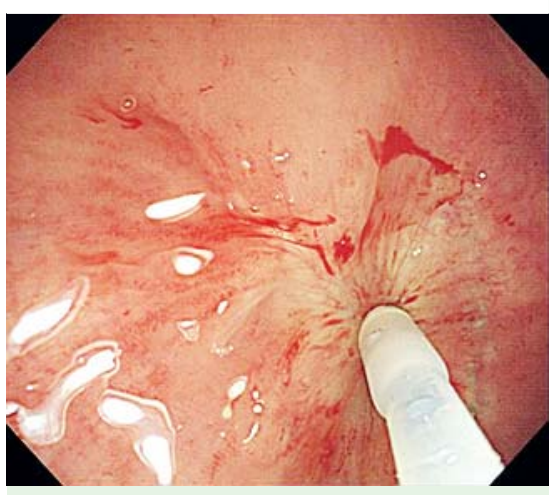

Fig. 2 Puncturing using the DualKnife at the center of the obstructed anastomotic site.

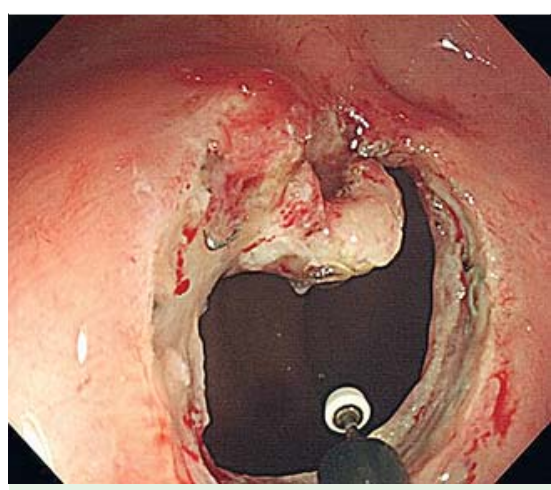

Fig. 3 Circumferential excision with the ITknife2 to the inner margin of the surgical staples.

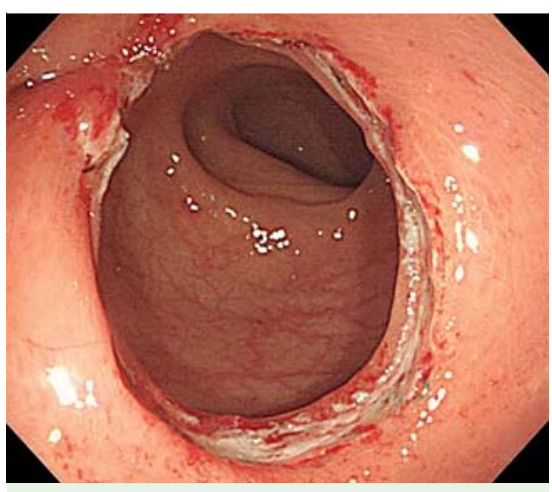

Fig.4 The enlarged hole was sufficient to enable free passage of the colonoscope. 
3 Bannura GC, Cumsille MA, Barrera AE et al. Predictive factors of stenosis after stapled colorectal anastomosis: prospective analysis of 179 consecutive patients. World J Surg 2004; 28: 921 - 925

4 Nguyen-Tang T, Huber O, Gervaz $P$ et al. Long-term quality of life after endoscopic dilation of strictured colorectal or colocolonic anastomoses. Surg Endosc 2008; 22: $1660-1606$
Bibliography

Dol http://dx.doi.org/

10.1055/s-0034-1364949

Endoscopy 2014; 46: E145-E146

(c) Georg Thieme Verlag KG

Stuttgart · New York

ISSN 0013-726X
Corresponding author

\section{Sang-Jeon Lee, MD, PhD}

Department of Surgery

Chungbuk National University Hospital

Chungbuk National University College of Medicine

776, 1 Sunhawn-ro

Heungdeok-gu

Cheongju 361-711

Korea

Fax: $+82-43-2666037$

colon@chungbuk.ac.kr 